\title{
Chronic pain syndromes
}

Department of

University, Ste-Foy,

Quebec, Canada

$S$ Carette

Correspondence to:

Dr S Carette,

Centre Hospitalier de

I'Université Laval, 2705

Boulevard Laurier, Ste-Fo

Accepted for publication

28 December 1995

\author{
Simon Carette
}

Chronic pain has traditionally been defined as pain lasting more than three to six months. Many conditions in rheumatology can produce chronic pain. These include diseases such as rheumatoid arthritis and osteoarthritis. Pain in these conditions can usually be attributed to specific pathological mechanisms such as inflammatory synovitis or joint destruction. Effective treatment modalities are available to relieve some, if not most, of the pain in these situations.

Over the past two decades or so, more attention has been given to previously existing conditions, now redefined as syndromes, that produce chronic musculoskeletal pain but in which the underlying pathophysiological mechanisms responsible for the pain have not been elucidated. These conditions have been arbitrarily divided into those causing diffuse versus regional pain. Fibromyalgia is by far the most common chronic diffuse musculoskeletal pain syndrome seen by rheumatologists. Myofascial pain syndromes (MPS) and repetitive strain syndromes (RSS) represent examples of chronic regional pain syndromes. These diffuse and regional pain syndromes have many features in common including the absence of an identifiable organic cause, behavioural maladaptations to pain, and much overlap in symptoms and signs (table). The purpose of this article is to review some of the recent concepts and controversies related to these three syndromes.

\section{Fibromyalgia}

The syndrome that we now call fibromyalgia has been known for a long time. The association of diffuse musculoskeletal pain, sleep disturbances, and exhaustion can be traced to biblical times. ${ }^{1}$ Various names have been used over the centuries to describe this association of symptoms as new explanations for their cause were proposed. ${ }^{2} \mathrm{~A}$ renewed interest in this condition followed the description by Moldofsky and Smythe of distinct electroencephalographic sleep anomalies in patients

Comparison of fibromyalgia (FM), myofascial pain syndrome (MPS), and repetitive strain syndrome (RSS)

\begin{tabular}{|c|c|c|c|}
\hline Variable & $F M$ & MPS & $R S S$ \\
\hline $\begin{array}{l}\text { Pain } \\
\text { Physical } \\
\text { examination }\end{array}$ & $\begin{array}{l}\text { Diffuse } \\
\text { Tender points }\end{array}$ & $\begin{array}{l}\text { Regional } \\
\text { Trigger points }\end{array}$ & $\begin{array}{l}\text { Regional } \\
\text { Tender points }\end{array}$ \\
\hline Fatigue & +++ & ++ & ++ \\
\hline Sleep disturbance & +++ & ++ & ++ \\
\hline $\begin{array}{l}\text { Psychological } \\
\text { distress }\end{array}$ & +++ & ++ & ++ \\
\hline Pathophysiology & Unknown & Unknown & Unknown \\
\hline
\end{tabular}

with widespread pain and tender points. ${ }^{3}$ This growing interest in studying fibromyalgia in recent years is reflected by the number of index entries extracted from Index Medicus, which have increased from 37 in 1974 to more than 500 since 1990 .

By contrast with the other chronic pain syndromes related to the musculoskeletal system, fibromyalgia is the only one for which validated classification criteria have been proposed. ${ }^{4}$ Thus, a patient with widespread pain as defined by pain affecting the axis and the right and left sides of the body, above and below the waist, and in whom tenderness can be shown on digital palpation of at least 11 of 18 predetermined sites can be classified as having fibromyalgia. Based on these criteria, $3.4 \%$ of women and $0.5 \%$ of men in the general population of Wichita, KS, USA were found to be affected. ${ }^{5}$ The prevalence increased with age, with highest values attained between 60 and 79 years. Seventy six per cent of affected patients had seen a physician in the preceding six months; two thirds took some form of pain medication and $19.7 \%$ had applied for, and $7 \cdot 3 \%$ had received, disability benefits. Fibromyalgia accounts for as many as $20 \%$ to $25 \%$ of new referrals to rheumatologists, ranking second after osteoarthritis. ${ }^{6}$

The aetiology of fibromyalgia is basically unknown. The finding that it occurs at least 10 times more often in women than men is still unexplained. ${ }^{7}$ No genetic predisposition has been documented. ${ }^{8}$ Whereas it has been suggested that fibromyalgia may in some cases arise after trauma, surgery, or a medical illness, such associations do not prove causality. ${ }^{9}$

Despite intensive research, the pathogenesis is not understood. ${ }^{10}$ No specific abnormalities have been found in the tender muscles of patients with fibromyalgia by light microscopy, histochemistry, or electron microscopy. ${ }^{11}$ The possibility that fibromyalgia could result from defects in muscle energy metabolism was suggested by studies in which local hypoxia ${ }^{12}$ and reduced high energy phosphate concentrations were demonstrated at sites of muscle tenderness. ${ }^{13} \mathrm{~A}$ recent study with phosphorus magnetic resonance spectroscopy reinforced this hypothesis by documenting a higher rate of phosphodiester resonance among the patients with fibromyalgia than among healthy subjects. ${ }^{14}$ However, another study using the same technique showed no difference in any of the measures of muscle energy metabolism in patients with fibromyalgia compared with controls carefully matched for their level of aerobic fitness. ${ }^{15}$ 
The role of disturbed sleep in the aetiology or perpetuation of symptoms of fibromyalgia has been studied extensively in the past 20 years. ${ }^{16}$ The documentation of $\alpha$ wave intrusion into stages 3 and 4 of the non-rapid eye movement sleep (NREM) was initially thought to be specific for the syndrome especially after symptoms of fibromyalgia were reproduced experimentally in healthy sedentary volunteers with artificial sleep manipulation. ${ }^{17}$ However, recent studies have shown that these electroencephalographic sleep anomalies lack both sensitivity ${ }^{18}$ and specificity. ${ }^{19-20}$

Several investigators have suggested the possibility that neuroendocrine abnormalities such as a deficiency in serotonin ${ }^{23-25}$ and hyothalamic-pituitary axis perturbations ${ }^{26}{ }^{27}$ could be implicated in the syndrome. These findings need to be confirmed in studies using controls matched for pain and sleep disturbances rather than normal subjects. So far, two studies have shown higher concentrations of substance $P$ in the cerebrospinal fluid of patients with fibromyalgia than in normal controls. ${ }^{28}{ }^{29}$ However, the significance of this potentially interesting finding was dampened when an inverse relation was found between the substance $P$ concentrations and the severity of pain which was the opposite of that expected if substance $P$ was a key factor in the pathophysiology of the syndrome. ${ }^{29}$

It is well accepted that pain perception can be influenced by multiple factors including past experiences, culture, personality, and a host of psychosocial factors. Patients with fibromyalgia and their family members have been shown to have had a greater history of depression. ${ }^{30}$ One recent study showed that previous sexual abuse, physical abuse, and drug abuse were higher in patients with fibromyalgia compared with control patients with rheumatic disease. ${ }^{31}$ These findings are in contrast with another study in which the prevalence and type of sexual abuse were not different between women with fibromyalgia and community controls. ${ }^{33}$ However, the abused patients with fibromyalgia reported significantly more symptoms than did the nonsexually abused women. Although these studies have been criticised because of the biases inherent in retrospective studies, ${ }^{33}$ they represent a step in the right direction because they consider the crucial issues of better defining the psychological background of those who develop these puzzling symptoms.

Because of the non-specific nature of the symptoms reported by the patients and the failure of research efforts to define specific disease markers, it is not surprising that significant controversy still surrounds the existence of fibromyalgia as a distinct syndrome. The absence of diagnostic tests, serological and radiological signs, and truly objective physical signs led Dudley Hart to suggest that fibromyalgia is a "common non-entity". ${ }^{34}$ Cohen and Quintner criticised the American College of Rheumatology criteria described previously on the basis that they were derived via a circular argument in which the gold standard was the opinion of experts known to be unconditional believers in the specificity of the condition. ${ }^{35}$ Using modifications of previously published criteria, fibromyalgia was found in only $0.75 \%$ of the Finish population. ${ }^{36}$ In this study, fibromyalgia was associated with a high risk of mental disorder and all subjects fulfilling the criteria for fibromyalgia also fulfilled the criteria for at least one other musculoskeletal disorder. This led the authors to conclude that there was little epidemiological support for the concept of fibromyalgia as being a distinct disorder. The specificity of tender points has also been questioned. ${ }^{37}$ In a cross sectional study conducted in two general practices in north west England, $40 \%$ of patients with chronic widespread pain had tender point counts of 11 or more. However, $19 \%$ of patients with regional pain and $5 \%$ with no pain also had as many tender points. Whereas the presence of tender points was related to complaints of pain, they were also independently associated with depression, fatigue, and poor sleep, suggesting that tender points are a measure of general distress rather than markers of a distinct disease entity.

At this time, I think that recognising the physical and psychological suffering of patients with these symptoms is really what matters, whether we call their condition "fibromyalgia" or "chronic diffuse pain syndrome". So far, all reports from tertiary referral centres that have looked at the prognosis of these patients indicate that symptoms and signs tend to persist with time in the vast majority. ${ }^{38-41}$ The outcome in patients from community based practices may be better. ${ }^{42}$ Tricyclic agents ${ }^{43-47}$ and aerobic exercises ${ }^{48} 49$ are the therapeutic modalities that have been most extensively studied. Both produce short term benefit in a small percentage of patients. By contrast, nonsteroidal anti-inflammatory drugs $^{44} 50$ and corticosteroids $^{51}$ are ineffective. Behaviour modification approaches have a lot of appeal as their primary objective is to de-emphasise the pain focus in favour of active patient participation towards increased function and return to full, unrestricted work and play. ${ }^{52}{ }^{53}$ However, their efficacy has yet to be evaluated in randomised controlled trials.

\section{Myofascial pain syndromes}

Even less is known about myofascial pain syndromes than about fibromyalgia. This denomination was introduced by Travell in the 1950 s to describe regional pain syndromes, often of sudden onset, characterised by the presence of trigger points. These points are defined as tender areas deep within the muscle belly which, when palpated, result in referred pain that reproduce the patient's pain complaint. ${ }^{54}$ The referred pain does not follow simple segmental patterns and is not necessarily situated in the same dermatome, myotome, or sclerotome as that of the trigger point. Specific patterns of pain referral have been described for all muscles of the body. ${ }^{55}$ It is thought that many regional pain conditions, including subsets of low back and cervical disorders, tension headache, and 
temporomandibular joint syndrome represent myofascial pain syndomes.

Trigger points are said to be located within taut bands of muscle fibres. These represent tense muscle fibres, ranging from a few millimetres to a centimetre in width, that are found by palpation along the longitudinal axis of the muscle among the normally slackened fibres. ${ }^{55}$ A transient muscle contraction, the local twitch response, can be induced by rolling the trigger point under the fingers. ${ }^{55}$ Trigger points have been described as being either active or latent. An active trigger point, when palpated, results in pain in the trigger point's reference zone which reproduces the pain that is a problem to the patient whereas a latent point is tender locally and may reproduce referred pain that is different from the patient's complaint. The distinction between trigger and tender points is currently the source of much debate.

One of the main problems to plague research over the years in this field has been the absence of agreement on a uniform definition of myofascial pain and trigger points. In an important study, experts on myofascial pain and fibromyalgia examined 23 subjects, including seven patients with fibromyalgia, eight patients with myofascial pain, and eight healthy subjects, while blinded to diagnosis. ${ }^{56}$ For the purpose of this study, an active trigger point included the following characteristics: local muscle tenderness, taut band, twitch response, and referred pain that reproduced the patient's complaint. A latent trigger point had similar characteristics except that the zone of reference, when present, did not correspond to the pain that was a problem to the patient. Important questions concerning the validity of the trigger point definition were raised by this study. Thus latent trigger points occurred in less than $3 \%$ of patients with myofascial pain. Taut bands and twitch responses, which are usual requirements for the diagnosis of trigger points, were found in equal proportions among patients with myofascial pain, patients with fibromyalgia, and healthy controls. Whereas active trigger points were found in only $1.3 \%$ of the muscle sites examined from healthy subjects, they occurred in an equal proportion of muscles from patients with myofascial pain $(17 \cdot 3 \%)$ and fibromyalgia $(17 \cdot 2 \%)$. When the requirement for the presence of taut bands and twitch response was eliminated from the definition of an active trigger point, the prevalence of trigger points increased to $38 \%$ in the patients with fibromyalgia and to only $23 \%$ in the patients with myofascial pain. The reliability of some aspects of the trigger point examination was also questioned because the experts differed significantly in their ability to identify taut bands and muscle twitches. In another study, different physical therapists were also unable to reliably determine the presence of trigger points in patients with low back pain. ${ }^{57}$ The findings from these studies cast significant doubts about the concept of myofascial pain syndromes as currently defined.

As is the case for fibromyalgia, the pathogenesis of myofascial pain is not known.
Various hypotheses have been postulated but none has been adequately tested. No controlled studies of histological findings using clear case definitions has been reported. Studies evaluating the electromyographic activity of trigger points have yielded conflicting results ${ }^{58} 59$ and so have studies looking at the clinical usefulness of thermography for the documentation of trigger points. ${ }^{6061}$

The psychosocial factors associated with the development and perpetuation of myofascial pain have received little attention. High levels of psychological distress have been documented in patients with myofascial pain syndrome. ${ }^{62}$ In a recent study, patients with low back pain considered to be of myofascial origin had higher levels of somatisation and phobia than patients with herniated disc syndrome. ${ }^{63}$

The best way to manage patients with a myofascial pain syndrome remains controversial. The removal of factors susceptible to "activate" trigger points such as sudden overloading and repetitive motion has been recommended as an essential component of management. The "stretch and spray" technique popularised by Travell and her colleagues, which consists of passively stretching the affected muscle fibres after applying a vapocoolant spray, has been claimed to be the most effective treatment modality. ${ }^{55}$ Unfortunately, this approach has not been evaluated in controlled trials. Local injection of trigger points with either local anaesthetics or corticosteroids have also been claimed to be effective. One controlled trial suggested that local anaesthetics were better than dry needling. ${ }^{64} \mathrm{~A}$ double blind crossover trial showed no beneficial effect of low level laser treatment in the management of myofascial pain. ${ }^{65}$

Until more controlled studies are conducted to better define myofascial pain and establish the validity and reliability of the trigger point examination, the interpretation of the medical literature will be extremely difficult and controversy surrounding this diagnosis and its treatment will remain

\section{Repetitive strain syndromes}

Much has been written about "repetitive strain syndromes" and the controversy that this entity generated, particularly in Australia where it reached an epidemic proportion during the 1980s. ${ }^{68-69}$ This syndrome, also known as "repetitive strain injury" (RSI), "occupational overuse syndrome", and in the United States, as "cumulative trauma disorder", defines a non-specific regional pain syndrome that develops in the context of work, in the absence of identifiable disease of the muscle-tendonbone unit. ${ }^{70}$ Typically, the pain starts in the wrist and forearm area and spreads within days to weeks to the arm, shoulder girdle, and neck regions. ${ }^{71}$ Those with the syndrome complain of poor sleep, score higher than controls on questionnaires evaluating anxiety and depression, and show pronounced disease conviction. ${ }^{72}$ Physical examination typically discloses areas of muscle tenderness, often in the same sites as described in fibromyalgia. Pain 
can be elicited by stressing the wrist, hand, and elbow joint capsules but there is no evidence of underlying synovitis. Grip strength is typically decreased despite a normal neurological examination. Skin rolling tenderness is often present over the upper tarpezius region. Some patients eventually develop a chronic widespread pain syndrome that satisfies the classification criteria for fibromyalgia.

Whether or not this syndrome can be causally related to particular work practices has been at the centre of controversy. ${ }^{65-69}$ Although no one will deny that symptoms of arm pain and fatigue can develop in the context of work, there is no scientific evidence that repetitive movements can cause the symptoms of repetitive strain injury. The significant difference in the prevalence of reported cases of repetitive strain injury in employees doing the same type of work and with the same equipment, suggests that psychosocial variables are far more important than specific work activities in the expression of the syndrome. ${ }^{73}$ The Australian epidemic has taught the world how misconceptions reinforced by the medical profession, unions, public, and the worker's compensation system have succeeded in transforming an essentially benign condition into a major public health problem. ${ }^{74}$ While the court decisions made in Australia and the United Kingdom ${ }^{75}$ have put an end to the epidemics of repetitive strain injury, this obviously does not mean that chronic pain syndromes developing in the workplace have disappeared. However, by deemphasising the role of work or specific movements in causing these symptoms, the real issues of causation and prevention can now be considered.

\section{Conclusion}

Whether we are dealing with a patient with fibromyalgia or with an individual with a chronic regional pain syndrome that has developed isidiously or in the context of work or trauma, an important and currently unresolved issue is to determine which personal and environmental factors may have led the patient to develop a chronic pain syndrome. This aspect of the clinical approach, unfortunately, is often neglected. Perhaps this is due to the fact that too little attention has been devoted by researchers to elucidate the risk factors associated with the development of these syndromes. The emphasis in the past 20 years, particularly concerning fibromyalgia, has been to search for biological markers of the condition. ${ }^{10}$ This approach may have done more harm than good by implying to the patient that they must wait and hope for a cure through medical science. The future of research in chronic pain syndromes must consider more thoroughly the psychological factors involved in the development of these conditions. Case-control studies, or preferably longitudinal studies, looking specifically at previous traumatic experiences, psychiatric history, job satisfaction, family stress, and financial constraints, to name a few, will help advance our understanding of these syndromes and hopefully provide better ways to prevent them.

Many thansk to Dr E Anne Langlois for her critical review of the manuscript.

1 Smythe H A. Fibrositis syndrome: a historical perspective. f Rheumatol 1989; 19 (suppl): 1-6.

Reynolds $M$ D. The development of the concept of fibrositis. $\mathcal{F}$ Hist Med Allied Sci 1983; 38: 5-35.

3 Moldofsky $H$, Scarisbrick P, England R, Smythe $H$. Musculoskeletal symptoms and non-REM sleep Musculoskeletal symptoms and non-REM sleep
disturbance in patients with "fibrositis syndrome" and disturbance in patients with "fibrositis syndrome"
healthy subjects. Psychosom Med 1975; 37: 341-51.

4 Wolfe F, Smythe H A, Yunus M B, et al. The American College of Rheumatology 1990 criteria for the classification of fibromyalgia. Arthritis Rheum 1990; 33: 19-31.

5 Wolfe F, Ross K, Anderson J, Russell I J, Hebert L. The prevalence and characteristics of fibromyalgia in the general population. Arthritis Rheum 1995; 38: 19-28.

6 White K P, Speechley M, Harth M, Ostbye T. Fibromyalgia in rheumatology practice: a survey of Canadian rheumatologists. F Rheumatol 1995; 22: 722-6.

7 Carette S, Dessureault $M$, Bélanger A. Fibromyalgia and sex hormones [letter]. $\mathcal{F}$ Rheumatol 1992; 19: 831 .

8 Horven S, Stiles T C, Holst A, Moen T. HLA antigens in primary fibromyalgia syndrome. $\mathcal{F}$ Rheumatol 1992; 19:
pher 1269-70.

9 Greenfield S, Fitzcharles M A, Esdaile J M. Reactive fibromyalgia syndrome. Arthritis Rheum 1992; 35: 678-81.

10 Carette S. Fibromyalgia 20 years later. what have we really accomplished? I Rheumatol 1995; 22: 590-4.

11 Yanus M B, Kalyan-Raman U P, Masi A T, Aldag J C. Electron microscopic studies of muscle biopsy in primary fibromyalgia syndrome: a controlled and blinded study. f Rheumatol 1989; 16: 97-101.

12 Lund N, Bengtsson A, Thorborg P. Muscle tissue oxygen pressure in primary fibromyalgia. Scand $\mathfrak{F}$ Rheumatol 1986; 15: 165-73.

13 Bengtsson A, Henriksson K G, Larsson J. Reduced highenergy phosphate levels in the painful muscles of patients with primary fibromyalgia. Arthritis Rheum 1986; 29: 817-21.

14 Jubrias S A, Bennett R M, Klug G A. Increased incidence of a resonance in the phosphodiester region of $P$ nuclear magnetic resonance spectra in the skeletal muscle of fibromyalgia patients. Arthritis Rheum 1994; 37: 801-7.

15 Simms R W, Roy S H, Hrovat M, et al. Lack of association between fibromyalgia syndrome and abnormalities in muscle energy metabolism. Arthritis Rheum 1994; 37: 794-800.

16 Moldofsky H. Sleep and fibrositis syndrome. Rheum Dis Clin North Am 1989; 15: 91-103.

17 Moldofsky H, Scarisbrick P. Induction of neurasthenic musculoskeletal pain syndrome by selective sleep stage musculoskeletal pain syndrome by selective
deprivation. Psychosom Med 1976; 38: 35-44.

18 Carette S, Oakson G, Guimont C, Steriade M. Sleep electroencephalography and the clinical response to amitriptyline in patients with fibromyalgia. Arthritis Rheum 1995; 38: 1211-7.

19 Moldofsky H, Lue F A, Saskin P. Sleep and morning pain in primary osteoarthritis. $\mathcal{F}$ Reumatol $1987 ; 14: 124-8$.

20 Hirsch M, Carlander B, Vergé M, et al. Objective and subjective sleep disturbances in patients with rheumatoid

21 Leventhal L, Freundlich B, Lewis J, Gillen K, Henry J, Dinges D. Controlled study of alpha-NREM sleep in patients with fibromyalgia [abstract]. Arthritis Rheum patients with fibromyal

22 Scheuler W, Kubicki S, Marquardt J, et al. The alpha-sleep pattern: quantitative analysis and functional aspects. In:
Koella W P, Obal F, Schultz H, Visser P, eds. Sleep '86 Koella W P, Obal F, Schul
Stutgart: Fischer, 1988 .

23 Yanus M B, Dailey J W, Aldag J C, Masi A T, Jobe P C. Plasma tryptophan and other amino acids in primary fibromyalgia - a controlled study. $\mathcal{F}$ Rheumatol 1992; 18: $90-4$.

24 Russell I J, Vaeroy H, Javors M, Nyberg F. Cerebrospinal fluid biogenic amine metabolites in fibromyalgia/fibrositis syndrome and rheumatoid arthritis. Arthritis Rheum 1992; 35: 550-6.

25 Russell I J, Michalek J E, Vipraio G A, Fletcher E M, Javors M A, Bowden C A. Platelet H-imipramine uptake receptor density and serum serotonin levels in patients with fibromyalgia/fibrositis syndrome. $\mathcal{F}$ Rheumatol 1992; 19: 104-9.

26 Bennett R M, Clark S R, Campbell S M, Burckhardt C S. Low levels of somatomedin $C$ in patients with the fow levels of somatomedin $C$ in patients with the fibromyalgia syndrome - a possible link between
muscle pain. Arthritis Rheum 1992; 35: 1113-6.

27 Crofford L J, Pillemer S R, Kalogeras K T, et al. Hypothalamic-pituitary-adrenal axis perturbations in Hypothalamic-pituitary-adrenal axis perturbations in
patients with fibromyalgia. Arthritis Rheum 1994; 37: patients

28 Vaeroy H, Helle R, Forre O, Kass E, Terenius L. Elevated CSF levels of substance $P$ and high incidence of Raynaud's phenomenon in patients with fibromyalgia: new features for diagnosis. Pain 1988; 32: 21-6.

29 Russell I J, Orr M D, Littman B, et al. Elevated cerebrospinal fluid levels of substance $P$ in patients with the 
fibromyalgia syndrome. Arthritis Rheum 1994; 11 1593-601.

30 Hudson J I, Hudson M S, Pliner L F, Goldenberg D I Pope H G Jr. Fibromyalgia and major affective disorders: a controlled phenomenology and family history study. $A m$ f Psychiatry 1985; 142: 441-6.

31 Boisset-Pioro M H, Esdaile J M, Fitzcharles M A. Sexual and physical abuse in women with fibromyalgia syndrome. Arthritis Rheum 1995; 38: 235-41.

32 Taylor M L, Trotter D R, Csuka M E. The prevalence of sexual abuse in women with fibromyalgia. Arthritis Rheum 1995; 38: 229-34.

33 Hudson J I, Pope H G. Does childhood sexual abuse cause fibromyalgia? Arthritis Rheum 1995; 38: 161-3.

34 Dudley Hart F. Fibrositis (fibromyalgia): a common nonentity? Drugs 1988; 35: 320-7.

35 Cohen M L, Quintner J L. Fibromyalgia syndrome, a problem of tautology. Lancet 1993; 342: 906-9.

36 Makela M, Heliovaara M. Prevalence of primary fibromyalgia in the Finnish population. BMf 1991; 303: 216-9.

37 Croft P, Schollum J, Silman A. Population study of tender point counts and pain as evidence of fibromyalgia. $B M \mathcal{F}$ 1994; 309: 696-9.

38 Felson D T, Goldenberg D L. The natural history of fibromyaloia. Arthritis Rheum 1986; 29: 1522-6.

39 Ongchi D R, Dill E R, Katz R S. How often do fibromyalgia patients improve? Arthritis Rheum 1990; 33: S136.

40 Norregaard J, Bulow P M, Prescott E, Jacobsen S, Danneskiold-Samsoe. A four-year follow-up study in fibromyalgia. Relationship to chronic fatigue syndrome. Scand Rheumatol 1993; 22: 35-8.

41 Ledingham J, Doherty S, Doherty M. Primary fibromyalgi syndrome: an outcome study. $B r \mathcal{F}$ Rheumatol 1993; 32: 139-42.

42 Granges G, Zilko P, Littlejohn G O. Fibromyalgia syndrome: assessment of the severity of the condition 2 years after diagnosis. $\mathcal{f}$ Rheumatol 1994; 21 : 523-9.

43 Carette S, McCain G A, Bell D A, Fam A G. Evaluation of amitriptyline in primary fibrositis: a double-blind, placebo-controlled study. Arthritis Rheum 1986; 29: placebo-c

44 Goldenberg D L, Felson D T, Dinerman H. A randomized, controlled trial of amitriptylione and naproxen in the treatment of patients with fibromyalgia. Arthritis Rheum 1986; 29: 1371-7.

45 Bennett R M, Gatter R A, Campbell S M, Andrews R P, Clark S R, Sarola J A. A comparison of cyclobenzaprin and placebo in the management of fibrositis: a doubleblind controlled study. Arthritis Rheum 1988; 31 1535-42.

46 Russell I L, Flether E M, Michalek J E, McBroom P C, Hester G G. Treatment of primary fibrositis/fibromyalgia syndrome with ibuprofen and alprazolan: a double-blind, placebo-controlled study. Arthritis Rheum 1991; 34: 552-60.

47 Carette S, Bell M J, Reynolds W J, et al. Comparison of amitriptyline, cyclobenzaprine, and placebo in the treatment of fibromyalgia: a randomized, dout

48 McCain G A, Bell D A, Mai F M, Halliday P E. A controlled study of the effects of a supervised cardiovascular fitness training program on the manifestations of primary fibromyalgia. Arthritis Rheum 1988; 31: 1135-41.

49 Burckhardt C S, Mannerkorpi K, Hedenberg L, Bielle A. A randomized, controlled trial of education and physical training for women with fibromyalgia. $\mathcal{f}$ Rheumatol 1994 ; 21: 714-20.

50 Yunus M B, Masi A T, Aldag J C. Short term effects of ibuprofen in primary fibromyalgia syndrome: a doubleibuprofen in primary fibromyalgia syndrome: a double527-32.

51 Clark S, Tindall E, Bennett R M. A double blind crossover trial of prednisone versus placebo in the treatment of fibrositis. $\mathcal{F}$ Rheumatol 1985; 12: 980-3.
52 Nelson W R, Walker C, McCain G A Cognitive behavioral treatment of fibromyalgia: preliminary findings. $\mathcal{f}$

53 White K P, Nielson W R. Cognitive behavioral treatment of fibromyalgia syndrome: a follow-up assessment. $\mathcal{F}$ Rheumatol 1995; 22: 717-21.

54 Travell J, Rinzler S H. The myofascial genesis of pain. Postgrad Med 1952; 11: 425-34.

55 Travell J G, Simons D G. Myofascial pain and dysfunction: the trigger point manual. Baltimore: Williams and Wilkins, 1983.

56 Wolfe F, Simons D G, Fricton J, et al. The fibromyalgia and myofascial pain syndromes: a preliminary study of tender points and trigger points in persons with fibromyalgia, myofascial pain syndrome and no disease. 7 Rheumatol 1992; 19: 944-51.

57 Nice D A, Riddle D L, Lamb R L, Mayhew T P, Rucker K Intertester reliability of judgments of the presence of trigger points in patients with low back pain. Arch Phys Med Rehabil 1992; 73: 893-8.

58 Durette M R, Rodriquez A A, Agre J C, Silverman J L. Needle electromyographic evaluation of patients with myofascial or fibromyalgic pain. Am f Phys Med Rehabil 1991; 70: 154-6.

59 Hubbard D R, Berkoff G M. Myofascial trigger points show spontaneous needle EMG activity. Spine 1993; 18: 1803-7.

60 Kruse R A, Christiansen J A. Thermographic imaging of myofascial trigger points: a follow-up study. Arch Phys Med Rehabil 1992; 73: 819-23.

61 Swerdlow B, Dieter J N I. An evaluation of the sensitivity and specificity of medical thermography for the documentation of myofascial trigger points. Pain 1992; 48 205-13.

62 Keefe F J, Dolan E. Pain behavior and pain coping strategies in low back pain and myofascial pain dysfunction syndrome patients. Pain 1986; 24: 49-56.

63 Cassisi J E, Sypert G W, Lagana L, Friedman E M Robinson M E. Pain, disability, and psychological functioning in chronic low back pain subgroups: myofascial versus herniated disc syndrome. Neurosurg 1993; 33: $379-86$.

64 Jaeger B, Skootsky S A. Double blind, controlled study of different myofascial trigger point injection techniques. Pain 1987; 31: S292.

65 Thorsen H, Gam A N, Jess M, et al. Low level laser therapy for myofascial pain in the neck and shoulder girdle. A double-blind, cross-over study. Scand $\mathcal{F}$ Rheumatol 1992; 21: $139-41$

66 Ferguson D. The "new" industrial epidemic. Med f Aust 1984; 140: 318-9.

67 Hadler N M. The Australian and New Zealand experiences with arm pain and backache in the workplace. Med $\mathcal{F}$ Aust 1986; 144: 191-5.

68 Cleland L G. "RSI": a model of social iatrogenesis. Med 7 Aust 1987; 147: 236-9.

69 Ferguson D A. "RSI": putting the epidemic to rest. Med f Aust 1987; 147: 213-4.

70 Littlejohn G O. Repetitive strain syndrome: an Australian experience. $\Im$ Rheumatol 1986; 13: 1004-6.

71 Miller M H, Topliss D J. Chronic upper limb pain syndrome (repetitive strain injury) in the Australian workforce: a systematic cross sectional rheumatological study of 229 patients. F Rheumatol 1988; 15: 1705-12.

72 Helme R D, LeVasseur S A, Gibson S J. RSI revisited: evidence for psychological and physiological differences from an age, sex, and occupation matched control group. Aust NZ $\mathcal{F}$ Med 1992; 22: 23-9.

73 McDermott F T. Repetition strain injury: a review of current understanding. Med f Aust 1986; 144: 196-200.

74 Littlejohn G O. Fibrositis/fibromyalgia syndrome in the workplace. Rheum Dis Clin North Am 1986; 15: $45-60$

75 Brahams D. Repetitive strain injury (reporting on Mughal $v$ Reuters). Lancet 1993; 342: 1168. 